RJTA

20,2

\section{Ascorbic acid treatment to improve the light fastness or as reducing agent on silk fabric dyed with pulverised natural dyes}

\author{
F.A. Faiz
}

Faculty of Applied and Creative Arts, Universiti Malaysia Sarawak, Kota Samarahan, Malaysia and Linton University College, Mantin, Malaysia

J.S.K. Ngo

Faculty of Applied and Creative Arts, Universiti Malaysia Sarawak, Kota Samarahan, Malaysia, and

K.B. Bujang

Institute of Research and Innovation, University Malaysia Sarawak, Kota Samarahan, Malaysia

\begin{abstract}
Purpose - This study aims to improve the natural dyeing recipe with better light fastness using ascorbic acid (vitamin C) with pulverised plant dyes.

Design/methodology/approach - Silk fabrics pre-mordanted with alum (aluminium ammonium sulphate) were dyed using six types of plant dyes available in Sarawak, Malaysia, namely, Engkerabai leaves (Psychotria viridiflora), Ketapang leaves (Terminalia catappa), mangrove bark (Ceriops tagal), Sepang wood (Caesalpinia sappan), mangosteen husk (Garcinia mangostana) and onion skin (Allium cepa). Then, the dyed samples were immersed in vitamin C. The dyed and vitamin C-treated silk samples were exposed to direct sunlight for $40 \mathrm{~h}$ to test whether vitamin $\mathrm{C}$ had any effect on the light fastness of the dyed samples.

Findings - It was found that the fabric samples using vitamin $\mathrm{C}$ for after-treatment, particularly Engkerabai, Ketapang, mangrove and mangosteen, exhibited better light fastness. The colours of the four samples changed and looked darker when compared to the non-treated fabric samples. However, it was observed that vitamin $\mathrm{C}$ had a reverse effect on Sepang wood and onion skin. The acidic aqueous solution of vitamin $\mathrm{C}$ discharged the dyed samples instead.

Originality/value - In conclusion, depending on the plant types, vitamin C can be used to improve the light fastness of natural dyes or as a reducing agent for natural dyes.
\end{abstract}

Keywords Pulverised plant dyes, Reducing agent, Light fastness, Direct dye, Natural fiber, Acid dye, Engkerabai leaves (Psychotria viridiflora), Ketapang leaves (Terminalia catappa), Mangrove bark (Ceriops tagal), Sepang wood (Caesalpinia sappan), Mangosteen husk (Garcinia mangostana), Onion skin (Allium cepa)

Paper type Research paper

Research Journal of Textile and Apparel

Vol. 20 No. 2, 2016

pp. 74-86

(c) Emerald Group Publishing Limited 1560-6074

DOI 10.1108/RJTA-11-2014-0036
The authors would like to thank Universiti Malaysia Sarawak (UNIMAS) for the support given to this study and development work. The authors would also like to thank UNIMAS for sponsoring this research (Grant No: DI/08/2008-04). 